\title{
They have gone, and now what? Understanding re-enrolment patterns in the Catalan public higher education system
}

\author{
David Rodríguez-Gómez $^{\mathrm{a}^{*}}$, Julio Meneses ${ }^{\mathrm{b}}$, Joaquín Gairín ${ }^{\mathrm{a}}$, Monica Feixas ${ }^{\mathrm{a}}$, José Luís \\ Muñoz ${ }^{\mathrm{a}}$ \\ ${ }^{a}$ Department of Applied Pedagogy, Universitat Autònoma de Barcelona, Spain; \\ ${ }^{\mathrm{b}}$ Internet Interdisciplinary Institute, Universitat Oberta de Catalunya, Spain.
}

\begin{abstract}
Studies of student re-enrolment patterns in Higher Education constitute, along with traditional studies of persistence and dropout, a key element for improving the quality of Higher Education Institutions. However, these studies tend to be limited as they are centred on a single institution, due to the lack of national-scale datasets for monitoring students between different institutions.
\end{abstract}

Using a longitudinal population-based dataset provided by the Catalan University Assurance Agency (AQU), which includes information records on 21,473 undergraduate students, this paper aims to develop and test an exploratory model of student re-enrolment, specifically in the Catalan public university system. We are not only interested in student re-enrolment, but also in whether they do so during the first year after dropout or in the same area of knowledge.

Results from logistic regression analysis revealed that although most students return to the university system in the first year after dropout, many of these change to a different area of knowledge, which is clear evidence of dysfunctional and inefficient guidance systems and university entrance. Findings provide a more accurate and complete picture of student re-enrolment behaviour and suggest the need to develop targeted policies to improve the efficiency and effectiveness of our university systems.

Keywords: higher education, dropout, retention, re-enrolment, multivariate analysis

\section{Introduction}

In the last half century, the increase in competition between universities, diversification, internationalisation and access by a higher percentage of the population to higher education has been accompanied by a growing interest in quality assurance in higher education (Westerheijden et al., 2007; Dick \& Tarí, 2013). Most research on quality assurance has focused, among other aspects, on the conceptual definition of quality in higher education (e.g., Houston, 2008); the applicability of quality management methodologies to the higher education sector (e.g., Pratasavitskaya \& Stensaker, 2010); the analysis of policies for quality in higher education (e.g., Elken \& Stensaker, 2011); the impact of quality assessment (e.g., Cardoso, Santiago \& Sarrico, 2012); and the definition of key indicators and dimensions for measuring quality (e.g., Krause, 2012).

\footnotetext{
* Corresponding author. Email: david.rodriguez.gomez@uab.cat
} 
In the latter, particular interest has been paid to persistence and dropout rates among university students, not only as key indicators to measure the performance and quality of university institutions, but also as symptoms of social and cultural development (Gridley et al., 2010; Rodríguez-Gómez, Feixas, Gairín \& Muñoz, 2015). Traditionally, studies of persistence and dropout have covered the identification of constructs combining different variables to improve explanatory models and, also, the analysis of specific factors (Herzog, 2005; Leveson, McNeil \& Joiner, 2013).

Although most of the literature tends to examine dropout as a permanent decision, in most cases it is temporary (Johnson, 2006; Stratton et al., 2008). We refer to this phenomenon as 'stop-out', when students temporarily interrupt their studies, or 'transfer-out', when students leave their home institution to enrol at another (Porter, 2003). Thus, building on earlier research, this study examines some of the factors that determine student re-enrolment (namely, stop-out and transfer) in the particular case of the Catalan public university system. We use a regional dataset on Catalonia to distinguish between those students who definitively drop out of Catalan universities, those who stop-out and those who transfer. Specifically, the main goals of this research are: (1) to construct and empirically test an exploratory model of student re-enrolment behaviour; and (2) to promote more effective policies to enhance student retention through a better understanding of attendance patterns among university students. In this regard, in the analysis of the differences in re-enrolment patterns, in terms of the initial area of knowledge and the time passed until re-enrolment, we explore the contribution of some key factors (i.e., gender, age, nationality) and the specific effects of the initial area of knowledge and of academic performance prior to dropping out of university.

This article first offers a brief review of the research covering dropout, stop-out and transfer-out behaviours. Secondly, it presents an empirical analysis of student reenrolment patterns, and it ends with the discussion and conclusions regarding the most significant findings.

\section{Stop-out and transfer-out in higher education}

While the factors determining the dropout and persistence of university students have been widely covered, there have been fewer efforts to understand the elements conditioning the return (i.e., stop-out or transfer-out) of students to the university system, and these have mainly focused on the Anglo-Saxon context (e.g., Schatzel et al., 2011). In this respect, the bibliographical review helps us to identify two large types of study of stop-out and transfer behaviours. The first are based on national databases with administrative and/or survey data (e.g., Jones-White et al., 2010). The second conduct surveys using samples from one or several higher education institutions (e.g., Oseguera \& Rhee, 2009). In both cases, the use of the timing dimension and the development of longitudinal analyses are fundamental to understand the complex nature of student enrolment patterns.

Previous studies have established that the factors usually associated with a return to education differ, statistically, from those mentioned in the case of university dropout (Herzog, 2005; Stratton et al., 2008). In this literature, different student behaviours can be observed among the factors associated with stop-out and with transfer (Stratton et al., 2007). On the one hand, the main factors associated with stop-out behaviour are related to certain sociodemographic attributes such as age, gender, ethnicity, occurrence and duration of previous stop-out spells, concurrent enrolment, attendance type, financial aid, place of residence, delayed enrolment and academic performance (Johnson, 2006; Stratton et al., 2008; Desjardins \& McCall, 2010). On the other hand, some of the 
differential factors explaining transfer-out behaviour include the duration of enrolment spells in the home institution, family income, academic background and college experience, among others (Herzog, 2005; Johnson \& Muse, 2012).

Although the aforementioned stop-out or transfer studies considerably improve our understanding of the factors explaining this type of behaviour, they are not that relevant to the Catalan university system, which is much more overcrowded and homogeneous, has little internal mobility of students and teaching staff and a lower proportion of international students (Hernández et al., 2010; Parellada, 2011). Likewise, the few studies of dropout, stop-out or transfer undertaken in Spain and Catalonia ${ }^{1}$ have tended to focus on single institutions, due to the lack of an adequate national-scale dataset hindering the tracking of student enrolment statuses after they have left their initial institution (e.g., Lassibille \& Navarro, 2008; Villar, 2010). Additionally, a solid understanding of student re-enrolment patterns in higher education requires empirical evidence outside of the Anglo-Saxon context.

\section{Higher Education in Catalonia}

The basic legal framework regulating the Catalan university system is defined by the Spanish central government and developed by the Catalan government. Nevertheless, the basic characteristics of the regional university systems are similar, which contributes to the low mobility of students, who tend to choose universities in their own city and/or region (MEC, 2008; OECD, 2010).

In the 2005/06 academic year, a reference year in order to contextualise the results presented herein, the Catalan university system comprised 7 public universities, 4 private universities and 1 online university (MEC, 2005). According to data from the Statistical Institute of Catalonia and the Catalan Government's Department of Economy and Knowledge, the whole undergraduate student body for Catalan public universities amounted to 205,045 (see Table 1).

\begin{tabular}{|l|c|c|c|c|c|}
\hline \multicolumn{6}{|c|}{ Table 1. Evolution of the undergraduate student body enrolled in the Catalan public } \\
university system. \\
\hline & \multicolumn{5}{|c|}{ Academic Year } \\
\hline & $\mathbf{2 0 0 1 - 0 2}$ & $\mathbf{2 0 0 2 - 0 3}$ & $\mathbf{2 0 0 3 - 0 4}$ & $\mathbf{2 0 0 4 - 0 5}$ & $\mathbf{2 0 0 5 - 0 6}$ \\
\hline Total & 204,566 & 204,867 & 210,017 & 204,746 & 205,045 \\
\hline Female & 109,140 & 109,129 & 110,648 & 109,568 & 109,970 \\
& $(53.35 \%)$ & $(53.27 \%)$ & $(52.69 \%)$ & $(53.51 \%)$ & $(53.63 \%)$ \\
\hline Male & 95,426 & 95,738 & 99,369 & 95,178 & 95,075 \\
& $(46.65 \%)$ & $(46.73 \%)$ & $(47.31 \%)$ & $(46.49 \%)$ & $(46.37 \%)$ \\
\hline Area of study & & & & & \\
\hline Arts & 34,979 & 23,048 & 22,204 & 21,792 & 21,155 \\
& $(17.10 \%)$ & $(11.25 \%)$ & $(10.57 \%)$ & $(10.64 \%)$ & $(10.32 \%)$ \\
\hline Experimental sciences & 12,245 & 13,642 & 13,107 & 12,696 & 12,502 \\
& $(5.99 \%)$ & $(6.66 \%)$ & $(6.24 \%)$ & $(6.20 \%)$ & $(6.10 \%)$ \\
\hline Health sciences & 19,904 & 18,334 & 18,517 & 17,930 & 18,499 \\
& $(9.73 \%)$ & $(8.95 \%)$ & $(8.82 \%)$ & $(8.76 \%)$ & $(9.02 \%)$ \\
\hline Social sciences and Law & 79,707 & 94,014 & 95,329 & 96,256 & 97,937 \\
& $(38.96 \%)$ & $(45.89 \%)$ & $(45.39 \%)$ & $(47.01 \%)$ & $(47.76 \%)$ \\
\hline Engineering & 57,731 & 55,829 & 60,860 & 56,072 & 54,952 \\
& $(28.22 \%)$ & $(27.25 \%)$ & $(28.98 \%)$ & $(27.39 \%)$ & $(26.80 \%)$ \\
\hline
\end{tabular}

Source: Statistical Institute of Catalonia and Department of Economy and Knowledge. 


\section{Method}

This study uses a population-based dataset, provided by the Catalan University Quality Assurance Agency (AQU), which includes records of undergraduate students who entered any of the Catalan public universities as freshmen in 2001-2002, and who were not enrolled for at least one term up to the 2005-2006 academic year. Each student was tracked for five years, resulting in a longitudinal database containing administrative data provided by each Catalan public university.

\subsection{Measures}

The measures used in this study are student gender, age, nationality, broad area of knowledge, credit hours earned, university re-enrolment, area of re-enrolment and firstyear re-enrolment (see table 2 for summary statistics).

Regarding the socio-demographic variables included, we expected gender, age, and nationality to be key factors explaining stop-out and transfer-out behaviours (e.g., Stratton et al., 2008). Age was intentionally recoded into four categories (i.e., '20 years and under', 'between 21 and 22 years', 'between 23 and 24 years', and ' 25 years and over'), clearly distinguishing between early leavers and mature students. The middle age group was divided in an attempt to conserve the variability of the original variable. Nationality was also recoded into three categories: Spanish, European, and NonEuropean.

Students' broad area of knowledge (i.e., arts, social sciences and law, engineering and health sciences) was included as prior studies have shown this to be associated to the risk of dropout (e.g., Hernández et al, 2010). In order to assess the effect of students' academic performance prior to dropout, the percentage of credit hours completed out of the total amount on the degree program before dropping out was also included as an independent variable (i.e., '20\% and under', 'between 21 and 50\%', 'between 51 and $80 \%$ ' and ' $81 \%$ and over'). The ratio of earned credit hours served not only as a measure for academic progress, but also as a proxy measure for commitment and academic integration (Johnson \& Muse, 2012).

The dependent variables are university re-enrolment, broad area of re-enrolment and first-year re-enrolment. University re-enrolment identifies the students that re-enrol at university after dropping out up to 2005-2006. This measure does not differentiate between undergraduate students that re-enrol for their course at their original university (stop-out) and those that do so for a different course and/or university (transfer-out), as the study focuses on the totality of the university system rather than any particular institution.

On the basis of a variable that indicates the broad area of knowledge pertaining to the new degree for which students enrol when returning to university, the area of reenrolment enables us to differentiate between students that re-enrol for the same broad area of knowledge and students that do not re-enrol for the same broad area of knowledge.

Finally, first-year re-enrolment shows the time in years between dropout and reenrolment. As occurs for dropout, most re-enrolments happen in the first year (Singell $\&$ Waddell, 2010), so we re-codify the data as a dichotomic variable that distinguishes between students that re-enrol in the first year (early re-enrolment), and those that do so later (late re-enrolment).

\subsection{Analysis}


To meet the goals of this study, we begin with descriptive analyses of our measures. After an initial exploration of the data, considering the dichotomic nature of the dependent variables and the nonmetric nature of the available explanatory variables, three interactive logistic models have been developed, including two-way interaction terms comprised of gender (moderator variable) and age and area of knowledge (focal variables): one on re-enrolment and two on the conditions under which re-enrolment is produced.

Logistic regression modelling, widely adopted in retention studies (e.g., Singell \& Waddell, 2010; Aina, 2013), is a particularly well suited method for studying the relationships between the independent variables (i.e., gender, age, nationality, area of knowledge and credit hours earned) and the dependent variables (i.e., university reenrolment, same area re-enrolment and first-year re-enrolment) and quantifying the corresponding partial and independent effects. Regression coefficients (B), standard errors (S.E.) and their corresponding exponentiated logistic coefficient $(\operatorname{Exp}(B))$ were calculated. Pseudo $\mathrm{R}^{2}$ measures (Cox and Snell $\mathrm{R}^{2}$ and Nagelkerke $\mathrm{R}^{2}$ ) and overall classification accuracy were also calculated to determine the goodness of fit of the models.

\section{Results}

Firstly, of the total dropouts registered, the most notable fact is that most dropouts are definitive, since only $37.5 \%$ correspond to the student population $(n=8053)$ that was registered as re-enrolling for the Catalan public university system up to 2005-2006 (see Table 2). As occurs with similar longitudinal studies (e.g., Herzog, 2005; Johnson, 2006), we assume the existence of students that are registered as dropouts but might reenrol at university institutions outside of the Catalan public system or that, within the same system, re-enrol later than the analysed period.

\begin{tabular}{|l|c|c|c|}
\hline \multicolumn{3}{|c|}{ Table 2. Dropout students in the Catalan public university system. Population } \\
distribution (\%). \\
\hline & $\begin{array}{c}\text { Initial dropout } \\
\text { students registered }\end{array}$ & $\begin{array}{c}\text { Re-enrolled students } \\
\text { (stop-out or transfer- } \\
\text { out) }\end{array}$ & $\begin{array}{c}\text { Long-term dropout } \\
\text { students }\end{array}$ \\
\hline Gender & & & \\
Female & 48.6 & 46.9 & 49.6 \\
Male & 51.4 & 53.1 & 50.4 \\
\hline Age & & & \\
20 years and under & 16.8 & 30.0 & 2.8 \\
Between 21 and 22 years & 30.2 & 40.1 & 20.6 \\
Between 23 and 24 years & 18.0 & 13.7 & 46.3 \\
25 years and over & 35.0 & 16.2 & 95.6 \\
\hline Nationality & & & 2.7 \\
Spanish & 97.0 & 99.2 & 1.7 \\
European & 1.8 & 0.3 & 19.4 \\
Non-European & 1.2 & 0.4 & 7.6 \\
\hline Area of Knowledge & & & 43.9 \\
Arts & 17.2 & 13.5 & 25.4 \\
Sciences & 9.2 & 11.9 & \\
Social Sciences and Law & 40.4 & 34.6 & \\
Engineering & 29.7 & 36.8 & \\
\hline
\end{tabular}




\begin{tabular}{|l|c|c|c|}
\hline Health Sciences & 3.5 & 3.2 & 3.6 \\
\hline Credit hours earned & & & \\
20\% and under & 76.1 & 83.1 & 71.9 \\
Between 21 and 50\% & 16.4 & 12.5 & 18.8 \\
Between 51 and 80\% & 4.9 & 3.8 & 5.5 \\
$81 \%$ and over & 2.5 & 0.5 & 3.8 \\
\hline Column totals & 100.0 & 37.5 & 62.5 \\
Percentage & $\mathbf{2 1 , 4 7 3}$ & $\mathbf{8 , 0 5 3}$ & $\mathbf{1 3 , 4 2 0}$ \\
N & & & \\
\hline
\end{tabular}

In the cases of dropout and long-term dropout, the highest concentrations of the population are for Social Sciences and Law (40.4\% and $43.9 \%$, respectively) while the lowest are for Health Sciences (3.5\% and 3.6\%, respectively). Likewise, it is observed that the highest percentage of dropouts in the Catalan context occurs among men (51.4\%) and students aged 25 years and over. Finally, while more than $76 \%$ of students who drop out have earned less than $20 \%$ of the necessary credit hours to complete their degree program, that proportion dropped to $2.5 \%$ for students with more than $81 \%$ of credit hours earned.

As for students that re-enrol in the Catalan university system, we observe that, apart from gender and performance, where the most numerous groups are still men $(53.1 \%)$ and students with performances below 20\% (83.1\%), there are slightly different distributions for the other variables considered. In this case, it is students aged between 21 and $22(40.1 \%)$ and people who originally enrolled for engineering (36.8\%) that return the most.

Observing the total values of bivariate analysis provided in Table 3, it is extremely important to highlight that, of the total number of people who re-enrol, only $12.7 \%$ do so in the area of knowledge of their original studies (those that were left) and $76.9 \%$ reenrol during the first year. Other than these global values, different behaviour is observed between the subpopulations regarding the return to university and the two types of re-enrolment considered (i.e., re-enrolment in the same area of knowledge and re-enrolment during the first year).

As regards the sociodemographic characteristics of the students, the results reveal differences in re-enrolment according to the three variables included (i.e., gender, age and nationality). A lower proportion of women re-enrol (36.2\%), and if they do they reenrol in the first year after dropout (75.9\%). However, although the values are very low, a higher proportion of women who re-enrol do so in the area of knowledge of their original course $(15.4 \%)$. As a result, and consistent with the results of similar studies (e.g., Johnson \& Muse, 2012), subsequent analyses of interactions considered gender to be a moderating variable. Likewise, younger students re-enrol more $(67.1 \%$ and $17.4 \%$ respectively) and in a higher proportion during the first year $(83.5 \%$ and $68.3 \%$, respectively) than older students. In contrast, older students who re-enrol do so to a greater extent in the same area of knowledge from which they dropped out $(16.6 \%)$. This sociodemographic profile is completed with the students' nationality. As expected, non-Spanish students present a lower percentage of re-enrolment: $7.2 \%$, in the case of European students, and $13.4 \%$ in the case of non-European students. 


\begin{tabular}{|c|c|c|c|}
\hline & $\begin{array}{c}\text { University re- } \\
\text { enrolment }\end{array}$ & $\begin{array}{c}\text { Same area re- } \\
\text { enrolment }\end{array}$ & $\begin{array}{l}\text { First-year re- } \\
\text { enrolment }\end{array}$ \\
\hline $\begin{array}{l}\text { Gender } \\
\text { Female } \\
\text { Male }\end{array}$ & $\begin{array}{l}36.2 \\
38.7\end{array}$ & $\begin{array}{l}15.4 \\
10.3\end{array}$ & $\begin{array}{l}75.9 \\
77.8\end{array}$ \\
\hline $\begin{array}{l}\text { Age } \\
20 \text { years and under } \\
\text { Between } 21 \text { and } 22 \text { years } \\
\text { Between } 23 \text { and } 24 \text { years } \\
25 \text { years and over }\end{array}$ & $\begin{array}{l}67.1 \\
49.8 \\
28.6 \\
17.4\end{array}$ & $\begin{array}{l}11.1 \\
12.3 \\
12.3 \\
16.6\end{array}$ & $\begin{array}{l}83.5 \\
75.8 \\
75.9 \\
68.3\end{array}$ \\
\hline $\begin{array}{l}\text { Nationality } \\
\text { Spanish } \\
\text { European } \\
\text { Non-European }\end{array}$ & $\begin{array}{c}38.4 \\
7.2 \\
13 .\end{array}$ & $\begin{array}{l}12.6 \\
25.0 \\
22.9\end{array}$ & $\begin{array}{l}77.1 \\
67.9 \\
42.9\end{array}$ \\
\hline $\begin{array}{l}\text { Area of Knowledge } \\
\quad \text { Arts } \\
\text { Sciences } \\
\text { Social Sciences and Law } \\
\text { Engineering } \\
\text { Health Sciences }\end{array}$ & $\begin{array}{l}29.4 \\
48.3 \\
32.1 \\
46.5 \\
34.9\end{array}$ & $\begin{array}{c}51.1 \\
28.5 \\
4.3 \\
1.6 \\
10.0\end{array}$ & $\begin{array}{l}68.3 \\
75.7 \\
74.2 \\
83.1 \\
75.0\end{array}$ \\
\hline $\begin{array}{l}\text { Credit hours earned } \\
20 \% \text { and under } \\
\text { Between } 21 \text { and } 50 \% \\
\text { Between } 51 \text { and } 80 \% \\
81 \% \text { and over }\end{array}$ & $\begin{array}{c}41.0 \\
28.5 \\
29.4 \\
7.7 \\
\end{array}$ & $\begin{array}{c}12.4 \\
13.9 \\
15.8 \\
7.1\end{array}$ & $\begin{array}{l}76.0 \\
80.6 \\
87.4 \\
50.0\end{array}$ \\
\hline $\begin{array}{l}\text { Totals } \\
\text { Percentage } \\
\text { N }\end{array}$ & $\begin{array}{l}37.5 \% \\
21,473\end{array}$ & $\begin{array}{c}12.7 \% \\
8,053\end{array}$ & $\begin{array}{c}76.9 \% \\
8,053\end{array}$ \\
\hline
\end{tabular}

Continuing with the bivariate exploration, we observe that engineering (1.6\%) and social sciences and law (4.3\%) recover fewer students in the re-enrolment process. Moreover, in the specific case of engineering, we note that the original student body in this area of knowledge re-enrols the most (46.5\%), only behind science $(48.3 \%)$, and does so earlier (83.1\%). Lastly, regarding credit hours earned, it is surprising to note that people with a higher percentage of successfully passed credits, above $80 \%$, have the lowest re-enrolment rate in the period studied $(7.7 \%)$, tend to change area the most ( $7.1 \%$ re-enrol in the same area of knowledge) and do so the latest (only $50 \%$ do so during the first year).

Secondly, to overcome the limitations of the bivariate analyses, three parallel multivariate logistic models are developed and tested, which help to explain how the changes in each of the independent variables are related to the different types of reenrolment analysed (i.e., re-enrolment in the university system, re-enrolment in the same area of knowledge, re-enrolment during the first year). Our strategy is based on the independent analysis of each explanatory variable, by means of the corresponding odds ratio (see Table 4). Thus, we will begin by discussing the effect of the sociodemographic characteristics (i.e., gender, age, and nationality); we will continue 
with the area of knowledge and credit hours earned, and, finally, we will study the role of gender as a moderating variable.

The overall adjustment of the first (university re-enrolment) and second model (same area re-enrolment) is acceptable, showing a pseudo $\mathrm{R}^{2}$ of 0.223 and 0.393 , respectively. The third model (first year re-enrolment) has a low adjustment with a pseudo $\mathrm{R}^{2}$ of 0.066 . However, all three models show an adequate classification accuracy of $70.3 \%$, $88.4 \%$, and $76.9 \%$, respectively.

Focusing on socio-demographic characteristics, gender has the most consistent influence, while student age and nationality play a more secondary role, with few exceptions. In contrast to the bivariate analysis, male students have a greater likelihood of both re-enrolment and the two re-enrolment types analysed (i.e., re-enrolment in the same area of knowledge and first year re-enrolment). These $\operatorname{Exp}(\mathrm{B})$ values indicate that the chances of returning to the same area of knowledge and first year re-enrolment for male students are, respectively, 50.3\% and 43.6\% higher (see second row in Table 4).

Age shows a negative simple main effect for university re-enrolment and first year reenrolment, with odds ratios ranging from 0.521 to 0.126 and from 0.674 to 0.421 , respectively. These values indicate that the older the student, the less likely they are to re-enrol and do so during the first year following dropout. On the contrary, and consistent with the abovementioned bivariate analyses, the probability of re-enrolling in the same area of knowledge is almost double for students of over 25 years of age, with an odds ratio of up to 1.909 compared with youngest students (i.e., students aged 20 years and under).

In the analysis of nationality, although European and Non-European students are less likely to re-enrol (odds ratios of 0.146 and 0.403 ) or to do so during the first year (odds ratios of 0.605 and 0.226 ) than their Spanish counterparts, when international students do re-enrol, they are more likely to remain in the same area of knowledge, with odds ratio values of 1.462 (46.2\% more likely) and of 2.417 (141\% more likely), respectively. For the sake of completeness, note the high standard error (S.E.) associated with the latter values. In this case, the S.E. may be high because the groups of individuals that belong to each level of the variable comprise small populations.

As regards the influence of the students' original area of knowledge on the probabilities of re-enrolment, we once again find similar behaviour between the first (university reenrolment) and the third model (first year re-enrolment). In both logistic regression models, the group of students with the greatest likelihood of re-enrolment are those from engineering. The conditional effects indicate that the probability of re-enrolment and re-enrolment during the first year after dropout for engineering students is two and almost three times larger than the probability of art students, with $\operatorname{Exp}(B)$ values of 2.097 and 2.756, respectively. In contrast, when we analyse the probability of reenrolment in the original area of knowledge, we observe that female students studying sciences, social sciences and law, engineering, and health sciences are less likely to reenrol for a course in the same area of knowledge than female arts students, with an odds ratio ranging from 0.458 to 0.034 (see fifth row in Table 4). 


\begin{tabular}{|c|c|c|c|c|c|c|}
\hline & \multicolumn{2}{|c|}{ University re-enrolment (1) } & \multicolumn{2}{|c|}{ Same area re-enrolment (2) } & \multicolumn{2}{|c|}{ First-year re-enrolment (3) } \\
\hline & B (S.E.) & $\operatorname{Exp}(B)$ & B (S.E.) & $\operatorname{Exp}(B)$ & B (S.E.) & $\operatorname{Exp}(B)$ \\
\hline Intercept & $0.356(0.066)$ & 1.427 & $-0.0143(0.115)$ & 0.867 & $1.008(0.107)$ & 2.740 \\
\hline $\begin{array}{c}\text { Gender } \\
\text { Female } \\
\text { Male }\end{array}$ & $0.133^{--}(0.105)$ & $\begin{array}{c}-- \\
1.142\end{array}$ & $0.407^{--}(0.190)$ & $\begin{array}{c}-- \\
1.503\end{array}$ & $0.362(0.173)$ & $\begin{array}{c}-- \\
1.436\end{array}$ \\
\hline $\begin{array}{l}\text { Age } \\
20 \text { years and under } \\
\text { Between } 21 \text { and } 22 \text { years } \\
\text { Between } 23 \text { and } 24 \text { years } \\
25 \text { years and over }\end{array}$ & $\begin{array}{c}-- \\
-0.652(0.061) \\
-1.450(0.073) \\
-2.069(0.069)\end{array}$ & $\begin{array}{c}-- \\
0.521 \\
0.234 \\
0.126\end{array}$ & $\begin{array}{c}-- \\
0.019(0.130) \\
-0.090(0.182) \\
0.647(0.163)\end{array}$ & $\begin{array}{l}-- \\
1.019 \\
0.914 \\
1.909\end{array}$ & $\begin{array}{c}- \\
-0.394(0.098) \\
-0.410(0.130) \\
-0.864(0.120)\end{array}$ & $\begin{array}{c}-- \\
0.674 \\
0.664 \\
0.421\end{array}$ \\
\hline $\begin{array}{l}\text { Nationality } \\
\text { Spanish } \\
\text { European } \\
\text { Non-European }\end{array}$ & $\begin{array}{c}-- \\
-1.927(0.201) \\
-0.908(0.190)\end{array}$ & $\begin{array}{c}-- \\
0.146 \\
0.403\end{array}$ & $\begin{array}{c}-- \\
0.380(0.539) \\
0.882(0.518)\end{array}$ & $\begin{array}{c}-\overline{7} \\
1.462 \\
2.417\end{array}$ & $\begin{array}{c}-- \\
-0.503(0.414) \\
-1.487(0.354)\end{array}$ & $\begin{array}{c}-- \\
0.605 \\
0.226\end{array}$ \\
\hline $\begin{array}{l}\text { Area of Knowledge } \\
\text { Arts } \\
\text { Sciences } \\
\text { Social Sciences and Law } \\
\text { Engineering } \\
\text { Health Sciences }\end{array}$ & $\begin{array}{c}-\overline{-} \\
0.362(0.082) \\
0.153(0.058) \\
0.741(0.078) \\
-0.051(0.110)\end{array}$ & $\begin{array}{l}-- \\
1.437 \\
1.166 \\
2.097 \\
0.950\end{array}$ & $\begin{array}{c}-- \\
-0.780(0.128) \\
-3.328(0.154) \\
-3.379(0.236) \\
-2.415(0.290)\end{array}$ & $\begin{array}{l}-\overline{-} \\
0.458 \\
0.036 \\
0.034 \\
0.089\end{array}$ & $\begin{array}{c}-- \\
0.507(0.140) \\
0.280(0.101) \\
1.014(0.138) \\
0.315(0.193)\end{array}$ & $\begin{array}{l}-- \\
1.660 \\
1.323 \\
2.756 \\
1.371\end{array}$ \\
\hline $\begin{array}{l}\text { Credit hours earned } \\
20 \% \text { and under } \\
\text { Between } 21 \text { and } 50 \% \\
\text { Between } 51 \text { and } 80 \% \\
81 \% \text { and over }\end{array}$ & $\begin{array}{c}-- \\
-0.098(0.044) \\
0.134(0.075) \\
-1.399(0.164)\end{array}$ & $\begin{array}{l}0.906 \\
1.144 \\
0.247\end{array}$ & $\begin{array}{c}-- \\
-0.044(0.119) \\
-0.081(0.194) \\
-0.793(0.716)\end{array}$ & $\begin{array}{c}-- \\
0.957 \\
0.922 \\
0.452\end{array}$ & $\begin{array}{c}-- \\
0.585(0.089) \\
1.272(0.179) \\
-0.757(0.319)\end{array}$ & $\begin{array}{l}-- \\
1.796 \\
3.569 \\
0.469\end{array}$ \\
\hline $\begin{array}{l}\text { Interactions (area of knowledge } * \mathbf{g} \\
\text { Arts } * \text { Female } \\
\text { Sciences * Male } \\
\text { Social Sciences and Law * Male } \\
\text { Engineering* Male } \\
\text { Health Sciences * Male }\end{array}$ & $\begin{array}{c}0.172(0.126) \\
-0.066(0.095) \\
-0.181(0.106) \\
0.305(0.202)\end{array}$ & $\begin{array}{l}-\overline{-} \\
1.188 \\
0.936 \\
0.835 \\
1.357\end{array}$ & $\begin{array}{c}-- \\
-0.329(0.195) \\
0.391(0.227) \\
-1.297(0.327) \\
0.550(0.441)\end{array}$ & $\begin{array}{l}-- \\
0.719 \\
1.479 \\
0.273 \\
1.732\end{array}$ & $\begin{array}{c}-- \\
-0.468(0.208) \\
-0.125(0.165) \\
-0.321(0.185) \\
-0.082(0.352)\end{array}$ & $\begin{array}{c}-- \\
0.626 \\
0.883 \\
0.726 \\
0.921\end{array}$ \\
\hline $\begin{array}{l}\text { Interactions (age * gender) } \\
20 \text { years and under* Female } \\
\text { Between } 21 \text { and } 22 \text { years * Male } \\
\text { Between } 23 \text { and } 24 \text { years * Male } \\
\text { Over } 25 \text { years * Male }\end{array}$ & $\begin{array}{c}-- \\
-0.066(0.088) \\
-0.097(0.103) \\
-0.150(0.096)\end{array}$ & $\begin{array}{l}-- \\
0.936 \\
0.908 \\
0.861\end{array}$ & $\begin{array}{c}-- \\
-0.187(0.198) \\
-0.014(0.265) \\
-0.782(0.245)\end{array}$ & $\begin{array}{c}-- \\
0.830 \\
0.986 \\
0.458\end{array}$ & $\begin{array}{c}-- \\
-0.310(0.140) \\
-0.200(0.183) \\
-0.111(0.167)\end{array}$ & $\begin{array}{c}-- \\
0.733 \\
0.818 \\
0.895\end{array}$ \\
\hline $\begin{array}{l}\text { Goodness-of-Fit } \\
\text { Cox \& Snell } \mathrm{R}^{2} \\
\text { Nagelkerke } \mathrm{R}^{2} \\
\text { Classification accuracy (\%) } \\
\mathrm{N} \text { total }\end{array}$ & $\begin{array}{c}0.164 \\
0.223 \\
70.3 \\
21,473\end{array}$ & & $\begin{array}{c}0.209 \\
0.393 \\
88.4 \\
8,053\end{array}$ & & $\begin{array}{c}0.043 \\
0.066 \\
76.9 \\
8,053\end{array}$ & \\
\hline
\end{tabular}

Binary dependent variables coded as no (0) and yes (1). 
Contrary to the initial exploratory analysis, when we observe the influence of credit hours earned on re-enrolment, the logistic models show that students with $21 \%$ or more credit hours completed are slightly less likely to return to the same area of knowledge after a stop-out spell, with $\operatorname{Exp}(\mathrm{B})$ values ranging from 0.452 to 0.957 . Examining reenrolment and first year re-enrolment behaviour models, students with medium-high performance (i.e., between 51 and $80 \%$ of credit hours completed) have higher odds ratios of 1.144 and 3.569 , respectively. Thus, for example, the chances of students who drop out after completing more than half of the course, but with one-fifth of the course remaining, are two and a half times higher than their lowest performance counterpart. Surprisingly, students who have completed practically all of the course credits (i.e., more than $80 \%$ ) are $75.3 \%$ less likely to re-enrol and $54.8 \%$ less likely to do so in the same area of knowledge, compared to those students with lower performance. In any case, as with the results associated with nationality, note the high standard error (S.E.) associated with these values.

Regarding the interpretation of interactions, considering the initial bivariate results and the literature review, we are interested in how gender 'moderates' the effect of both age and area of knowledge (i.e., focal independent variables) on re-enrolment and the two re-enrolment types analysed (i.e., re-enrolment in the same area of knowledge and first year re-enrolment). It is important to note that both credit hours earned and nationality were initially considered in the interactions, but in no case did the models improve (i.e., increase in the percentage of cases correctly classified and pseudo $\mathrm{R}^{2}$ ) and consequently were removed from the final logistic models.

Focusing on the product term coefficients obtained, different values for the odds ratios imply that the effect of area of knowledge and age varies depending on gender. Let us first compare the odds ratio for the interaction between area of knowledge and gender. It can be stated that male students from health sciences are more likely to re-enrol $(35.7 \%$ more likely) and to do so in the same area of knowledge ( $73.2 \%$ more likely), while their likelihood of re-enrolling during the first year is almost identical to the reference group (i.e., female students from arts).

Finally, if the interaction between age and gender is observed, it seems clear that all of the groups are less likely to re-enrol, to do so in the same area of knowledge and during the first year after dropout, when compared with female students younger than 21 .

\section{Discussion}

In this article we have examined the re-enrolment patterns of students in a public university system. Evidently, university policies must be directed, first, at reducing dropout and stop-out, but once students have left university, it is crucial to understand re-enrolment behaviour and, especially, re-enrolment in the same area of knowledge (associated to transfer-out models) and early re-enrolment, as long duration stop-outs 'lead to subsequent stop-outs and reduce graduation chances even further' (DesJardins $\&$ McCall, 2010, p. 536). The results of this study show that, although three quarters of students that drop out re-enrol for the university system during the first year after dropping out, the vast majority decide to change their area of knowledge during their second enrolment spell, which could be either evidence of clearly dysfunctional and inefficient guidance and university entrance systems (Bowles, Fisher, McPhail, Rosenstreich \& Dobsonm, 2014) or part of a career plan (O’Keefe, Laven \& Burgess, 2011).

Specifically, regarding university re-enrolment, our findings demonstrate that women, 
students over 25 years, international students, those from health sciences and those with over $80 \%$ of their credit hours earned are the least likely to re-enrol. These findings are consistent with previous studies indicating that student attributes (e.g., age, gender, residency status) are related to returning (e.g., Herzog, 2005), as well as with studies indicating that students with a higher percentage of credit hours earned are less likely to re-enrol after departure (e.g., Johnson \& Muse, 2012). For instance, the study suggests a strong connection between age, nationality and re-enrolment probabilities, which questions non-traditional student policies, especially those addressed at both international students and students over 25, as stated in previous studies (Kahu, Stephens, Leach \& Zepke, 2013).

Focusing on transfer-out patterns, the bivariate analysis shows that almost $90 \%$ of students that re-enrol for university decide to change their area of knowledge and, therefore, degree program. Multivariate analysis can be used to estimate the likelihood of transfer-out, which acts as a measure of 'at-risk-status' and therefore provides clues about the type of students on which guidance and retention policies should be focused. For example, and consistent with the expected results, this study suggests that the initial area of knowledge is one of the most important predictors of transfer-out behaviour. This is particularly true for engineering students, who, probably due to the strict permanency policies ${ }^{2}$ of such courses, are compelled to drop out and to continue their university studies in a different area of knowledge. Previous studies have also highlighted similar problems associated to engineering students (e.g., Lassibille \& Navarro, 2008; Min, Zhang, Long, Anderson \& Ohland, 2011).

Also, after controlling for the effect of socio-demographics and area of knowledge, the percentage of credit hours earned is still, as in dropout studies, an important factor (Singell \& Waddell, 2010). However, unlike the results of similar studies (e.g., Johnson, 2006), students with a higher number of earned credits do not tend to return to the same area of knowledge, and thus lose a large number of credit hours in the transition process.

Regarding the stop-out spell, researchers have started to explore the effects of the occurrence and duration of enrolled and non-enrolled episodes on students' chances of graduation and subsequent spells, as well as the factors explaining these states (e.g., DesJardins, Ahlburg \& McCall, 2006). Like these prior studies, our results show that the percentage of credit hours earned, as a proxy measure of previous spell duration (see Johnson and Muse, 2012, for a discussion), are substantially related to the probability of first-year re-enrolment. However, contrary to some existing studies (e.g., Ishitami, 2008), the first-year re-enrolment model presented here shows that students who are in the last stage of their degree (students over 25 and with a higher percentage of credit hours earned) are the least likely to re-enrol early, when compared with students who experience a stop-out spell early in their first enrolment. Once again, the area of knowledge is revealed as one of the factors that most consistently explain early reenrolment.

In a nutshell, our findings regarding student re-enrolment patterns in higher education suggest the existence of the students that Grubb (1991) calls 'experimenters' and who drop out from their initial courses after a short period of time and with very few credits passed, and re-enrol for a different area of knowledge the year immediately after dropping out. This type of student is more common in those university systems that allow students to access courses or universities that they did not choose at first. There is also a large group of students that, after dedicating several years to their university education and almost completing their studies, decide to drop out, with a very low 
likelihood of re-enrolling and when they do, this tends to be after a long non-enrolment spell and in a different area of knowledge. This further emphasizes, on the one hand, the importance of early detection of students that are at risk of early departure and reenrolment (i.e., 'experimenters') and, on the other, the need to develop policies that avoid the dropout and transfer-out of senior students with more than $80 \%$ of their credit hours earned.

So, beyond the size of interaction effects, our analysis shows the clear influence among the considered factors, thus showing how complex the enrolment phenomenon is. While many studies have performed extrapolations to the whole population, using samples or populations from a single institution, this study is not limited to a single institution. The re-enrolment models presented here are taken from the whole student population that dropped out from and re-entered the Catalan university system between 2001/02 and 2005/06, thus adapting the universe better than previous studies did.

However, this research is limited in several ways. First, considering the scarce and disperse institutional data collected by the university system, the findings should be treated with caution and viewed as an initial exploration of factors affecting student reenrolment. In this regard, it is impossible to obtain better explanations for the persistence behaviour of students if the institutional student data collection systems do not establish a unified protocol and incorporate some of the elements that other studies in the prior literature review suggest as explanatory of such behaviour (e.g., families' level of education and socio-economic status, university entrance grade, method of access, performance, student preferences, financial aid). The use of much more specific measures that consider specific personal, social and institutional factors are necessary in order to make a more complex and in-depth analysis of university re-enrolment. Additionally, considering the importance of the temporal dimension in understanding the longitudinal and complex nature of student enrolment patterns, event history methods or survival analyses are needed for a better understanding of whether and when students re-enrol (Singer \& Willett, 2003).

Complementarily, a mixed method approach, combining surveys and interviews, would offer a better understanding of re-enrolment patterns in higher education by converging both quantitative (broad numeric trends) and qualitative (detailed views) data (Creswell, 2009). A closed-ended questionnaire would complement the institutional dataset by focusing on some specific measures of university student attendance patterns (e.g., attitudes, beliefs, expectations, criteria for choice of course, etc.), both before and after the first enrolment, dropout and re-enrolment. Qualitative data would help to corroborate our survey's findings and also offer the opportunity to generate an in-depth understanding of the complexity of student attendance behaviour, complementing and reinforcing the results of other qualitative studies of stop-out and transfer-out behaviours (e.g., Bowles et al., 2014; Tobolowsky \& Cox, 2012). Also, although some interesting studies have already analysed stop-out and transfer-out from a qualitative perspective, we should continue to use this critical approach in order to gain a better understanding of social and cultural issues associated to these behaviours.

\section{Conclusion}

Education administrations and society should be aware of the political, economic and social problems involved in the dropout, stop-out and transfer-out phenomenon in the university system. The study presented here follows on from many similar ones of university students' attendance behaviour, and takes a step further by focusing on the reenrolment patterns of the whole student population in a public university system. The 
findings commented on above suggest the need to set up plans for transition into university, and for reception and accompaniment while there, that include the instruments and supports required to avoid, first, student dropout and, second and once dropout has occurred, the transfer of students to other areas of knowledge and/or universities. These plans require, on the one hand, joint action involving all university agents and structures, ensuring the complementarity of guidance activities of different origin (university, school and degree) and, on the other, the combination of general policies with actions that are as personalised as possible.

In short, the results shown here are of particular interest to policy makers and encourage the design of more effective and targeted institutional strategies and policies for specific groups that address each type of re-enrolment and thus improve the performance of our university systems.

\section{Endnotes}

1. Catalonia is an autonomous region in the north of Spain, self-governed through its own Parliament, with authority in numerous areas such as local government, justice, commerce, transportation, housing, health, public safety, social welfare, language, culture and education.

2. A full-time undergraduate student must pass at least 12 of the 60 credits in the first academic year and a minimum of 42 to 60 credits, depending on the programme, during the first two years.

\section{References}

Aina, C. (2013). Parental background and university dropout in Italy. Higher Education, $65(4), 437-456$.

Bowles, A., Fisher, R., McPhail, R., Rosenstreich, D., \& Dobson, A. (2014). Staying the distance: students' perceptions of enablers of transition to higher education. Higher Education Research \& Development, 33(2), 212-225.

Cardoso, S., Santiago, R. \& Sarrico, C. S. (2012). The impact of quality assessment in universities: Portuguese students' perceptions. Journal of Higher Education Policy and Management, 34(2), 125-138.

Creswell, J. (2009). Research design: Qualitative, quantitative, and mixed methods approaches. Thousand Oaks: SAGE.

Denzin, N. K., \& Lincoln, Y. S. (Eds.). (2011). The SAGE handbook of qualitative research. Thousand Oaks: SAGE.

DesJardins, S. L. \& McCall, B. P. (2010). Simulating the effects of financial aid packages on college student stopout, reenrollment spells, and graduation chances. The Review of Higher Education, 33(4), 513-541.

Desjardins, S. L., Ahlburg, D. A. \& McCall, B. P. (2006). The effects of interrupted enrollment on graduation from college: racial, income and ability differences. Economics of Education Review, 25(6), 575-590.

Dick, G. \& Tarí, J. J. (2013). A review of quality management research in higher education institutions. Working Paper Series, 274, 2-36. 
Elken, M. \& Stensaker, B. (2011). Policies for quality in higher education coordination and consistency in EU-policymaking 2000-2010. European Journal of Higher Education, 1(4), 297-314.

Gridley, J. M., Hampson, G. P., Wheeler, L. \& Bereded-Samuel, E. (2010). From Access to success: an integrated approach to quality higher education informed by social inclusion theory and practice. Higher Education Policy, 23(1), 123-147.

Grubb, W. N. (1991). The decline of community college transfer rates: evidence from national longitudinal surveys. Berkeley: University of California.

Hernández, J., Pérez, J. \& Hernández, J. (2010). La Universidad Española en cifras. Madrid: CRUE.

Herzog, S. (2005). Measuring determinants of student return vs. dropout/stopout vs. transfer: A first-to-second year analysis of new freshmen. Research in Higher Education, 46(8), 883-928.

Houston, D. (2008). Rethinking quality and improvement in higher education. Quality Assurance in Education, 16 (1), 61-79.

Ishitani, T. T. (2008). How do transfers survive after "transfer shock"? A longitudinal study of transfer student departure at a four-year institution. Research in Higher Education, 49(5), 403-419.

Johnson, I. Y. (2006). Analysis of stopout behaviour at a public research university: the multi-spell discrete- time approach. Research in Higher Education, 47(8), 905-934.

Johnson, I. Y., \& Muse, W. B. (2012). Student swirl at a single institution: The role of timing and student characteristics. Research in Higher Education, 53(2), 152-181.

Jones-White, D. R., Radcliffe, P. M., Huesman Jr, R. L., \& Kellogg, J. P. (2010). Redefining student success: Applying different multinomial regression techniques for the study of student graduation across institutions of higher education. Research in Higher Education, 51(2), 154-174.

Kahu, E. R., Stephens, C., Leach, L., \& Zepke, N. (2013). The engagement of mature distance students. Higher Education Research \& Development, 32(5), 791-804.

Krause, K. L. (2012). Addressing the wicked problem of quality in higher education: theoretical approaches and implications. Higher Education Research \& Development, 31(3), 285-297.

Lassibille, G., \& Navarro, L. (2008). Why do higher education students drop out? Evidence from Spain. Education Economics, 16(1), 89-105.

Leveson, L., McNeil, N., \& Joiner, T. (2013). Persist or withdraw: the importance of external factors in students' departure intentions. Higher Education Research \& Development, 32(6), 932-945.

MEC (2008). Datos básicos del Sistema Universitario Español. Curso 2008-2009. Madrid: Ministerio de Ciencia e Innovación.

MEC (2005). Datos y cifras del sistema universitario. Madrid: Ministerio de Educación y Ciencia.

Min, Y., Zhang, G., Long, R. A., Anderson, T. J., \& Ohland, M. W. (2011). Nonparametric survival analysis of the loss rate of undergraduate engineering students. Journal of Engineering Education, 100(2), 349373. 
OECD (2010). Higher Education in Regional and City Development. The Autonomous Region of Catalonia, Spain. Paris: OECD.

O'Keefe, M., Laven, G., \& Burgess, T. (2011). Student non-completion of an undergraduate degree: wrong program selection or part of a career plan?. Higher Education Research \& Development, 30(2), 165-177.

Oseguera, L., \& Rhee, B. S. (2009). The influence of institutional retention climates on student persistence to degree completion: A multilevel approach. Research in Higher Education, 50(6), 546-569.

Parellada, M. (Ed.) (2011). Informe CYD 2011. Barcelona: Fundación Conocimiento y Desarrollo.

Porter, S. R. (2003). Understanding retention outcomes: using multiple data sources to distinguish between dropouts, stopouts, and transfer-outs. Journal of College Student Retention, 5(1), 53-70.

Pratasavitskaya, H. \& Stensaker, B. (2010). Quality management in higher education: towards a better understanding of an emerging field. Quality in Higher Education, 16(1), 37-50.

Rodríguez-Gómez, D., Feixas, M., Gairín, J., \& Muñoz, J. L. (2015). Understanding Catalan university dropout from a cross-national approach. Studies in Higher Education, 40(4), 690-703.

Schatzel, K., Callahan, T., Scott, C. J. \& Davis, T. (2011). Reaching the non-traditional stopout population: a segmentation approach. Journal of Marketing for Higher Education, 21(1), 47-60.

Singell, L. D., \& Waddell, G. R. (2010). Modeling retention at a large public university: can at-risk students be identified early enough to treat?. Research in Higher Education, 51(6), 546-572.

Singer, J.D., and Willett, J.B. (2003). Applied longitudinal data analysis. New York: Oxford University Press.

Stratton, L. S., O’Toole, D. M., \& Wetzel, J. N. (2007). Are the factors affecting dropout behavior related to initial enrollment intensity for college undergraduates?. Research in Higher Education, 48(4), 453-485.

Stratton, L. S., O'Toole, D. M. \& Wetzel, J. N. (2008). A multinomial logit model of college stopout and dropout behavior. Economics of Education Review, 27(3), 310331.

Tobolowsky, B. F., \& Cox, B. E. (2012). Rationalizing neglect: An institutional response to transfer students. The Journal of Higher Education, 83(3), 389-410.

Villar, A. (2010). Del abandono de estudios a la reubicación universitaria. Revista de la Asociación de Sociología de la Educación, 3(2), 267-283.

Westerheijden, D. F., Stensaker, B., \& Rosa, M. J. (Eds.). (2007). Quality assurance in higher education: trends in regulation, translation and transformation (Vol. 20). Dordrecht: Springer. 